\title{
Improving Teaching and Learning Process through Establishment of Centre for Engineering Education Development - An initiative at KG College of Engineering and Technology
}

\author{
Sandhya Tuti', Rohit Kandakatla ${ }^{2}$, Syed Khamruddin ${ }^{3}$ \\ 1,2Department of Electronics and Communication Engineering \\ KG Reddy College of Engineering and Technology, Hyderabad \\ ${ }^{3}$ Department of Electrical and Electronics Engineering, \\ KG Reddy College of Engineering and Technology, Hyderabad \\ ${ }^{1}$ sandhyatutiece@kgr.ac.in \\ ${ }^{2}$ rohit.kandakatla@gmail.com \\ ${ }^{3}$ syedkhamruddin@kgr.ac.in
}

\begin{abstract}
The evolution of Engineering Education (EE) in India has been drastic from the British era to the present day. EE in India started during the British era and focused mainly on civil engineering. In 1945 a Government Committee was appointed to suggest options for advanced technical education in India which recommended the establishment of higher technical institutes based on the Massachusetts Institute of Technology in the four regions of India which resulted in setting up five Indian Institutes of Technology and the 20 Regional Engineering colleges just after independence was one of the first milestone achieved by Independent India. Then, there are a large number of State Government Engineering Colleges, often affiliated to a University and having a limited or no autonomy about curriculum, examinations, degree granting, etc. The great demand for engineering and technical education has led to the mushrooming of a large number of private engineering colleges. Since the establishment of IIT Kharagpur in 1951, India has a total of 3,393 engineering colleges as on May, 2012
\end{abstract}

In spite of the large number of engineering colleges in India, as per the third edition of the National Employability Report, Engineering Graduates - 2014, only $18.33 \%$ of the Indian engineers are employable and only about $18.09 \%$

\footnotetext{
Sandhya Tuti ${ }^{1}$

${ }^{1}$ Department of Electronics and Communication Engineering

KG Reddy College of Engineering and Technology, Hyderabad

${ }^{1}$ sandhyatutiece@kgr.ac.in
}

actually get a job. This alarming survey indicates the need of a paradigm shift in today's school of engineering learning and training so that we may not only target increased employability but also set our eyes on ameliorating research and innovation into Engineering Education.

This paper presents the work conducted by the Centre of Engineering Education Development (CEED) at KG Reddy college of Engineering and Technology, which was established to continuously work towards improving the teaching learning process by implementation of new pedagogies. The focus will be on implementation of active learning into the lecture delivery, it's impact on the student's, subsequent results and the future scope of work.

Keywords: Engineering Education, CEED, Active Learning

\section{Introduction}

Everything else has accelerated but schools have not; so schools have become more disconnected. The walls between schools and the outside need to be more permeable. Interview with Larry Rosen stock, CEO of High Tech High Network, San Diego, California

Education is the dominant model of evident in most places today. It is a model that is receding more and more rapidly as the forces of new pedagogies, and new change leadership, in an educational context that is overdue for transformation. CEED is established is about a radical change in the relationships between all the key players in learning: students, teachers, technologies, college cultures, 
and assessments. The report is also about how and why change is occurring more organically than ever before.

\section{Background}

"Active Learning" is, in short, anything that students do in a classroom other than merely passively listening to an instructor's lecture. This includes everything from listening practices which help the students to absorb what they hear, to short writing exercises in which students react to lecture material, to complex group exercises in which students apply course material to "real life" situations and/or to new problems. We initially started a new initiative to improve student engagement in the classroomby introducing student presentations in the classroom. We received a very response/feedback from the students who have seen a considerable improvement in their speaking skill and the subject knowledge.

In order to learn and gain more exposure in the field of engineering education, we have attended the $1^{\text {st }}$ and $2^{\text {nd }}$ International Conference on Transformations in Engineering Education (ICTIEE) in 2014 and 2015, at Hubli and Bangalore respectively Our major breakthrough was during the teacher certification program conducted by the Indo US Collaboration in Engineering Education (IUCEE) in association with International Society for Engineering Education (IGIP) where we introduced to different teaching and learning methodologies and mentored by experts in the field engineering education from around the world.

In order to share our learning in the above-mentioned programs with the entire faculty and to improve teaching learning Process established a Center for Engineering Education Development (CEED) at KGReddy College of Engineering and Technology (KGRCET).

\section{Faculty Training Workshop}

As the first initiative under the newly established CEED, we designed a 2-day faculty development workshop by considering three different modules such as preparation, delivery and assessment of the course with the below 4 major contents:

\section{A. Characteristics of $21^{\text {st }}$ Century Learners}

Today's digital kids think of information and communications technology(ICT) as something akin to oxygen. It's what they breathe, and it's how they live. They use ICT to meet, plate, date, learn, acknowledge each other and form their personal identities.[1]

Students born after the 1980's are known as the millennial learners, they are also known as Generation Next, Generation Y, and digital learners. These students have various personality traits such as

- Close affinity with technology

- Used to a lot of attention from the parents/family.

- Work best in relaxed environment.

- $\quad$ Enjoy social interaction, researching information and autonomy.

- Short attention span
The learning needs of the millennial learner had considerably changed since the past century. They

- $\quad$ Prefers open, transparent and fair interaction.

- Learn best when the content is relevant and presented in a rationale manner.

- Learn best when content is presented in multiple modes - visual, audio, games, and contests.

- $\quad$ Expect closer interaction with the faculty.

- Learn well in group/collaborative activities.

- Learn best in a relaxed environment.

- Enjoy challenging research-based activities.

By taking into account the various characteristics of the $21^{\text {st }}$ century learner, we proposed the following techniques to students to improve the student learning of the subject.

1) Make content relevant: Whenever possible connect content to the real world. This is possible for most topics in engineering, which is so closely linked to life.

2) Partner with Technology: Use different strategies/ technology options whenever possible

3) Make yourself accessible: Encourage them to communicate with you (e-mail is an excellent tool); support the shy/weaker students to develop confidence.

4) Regular Assessment: Embed assessment in everyday instruction. This will ensure regular review and repetition leading to enhanced student performance and confidence.

5) Plan and Implement group activities: Plan activities regularly which can be conducted in pairs, small groups and large groups.

6) Provide constructive feedback: Positive reinforcement is said to be one of the most powerful tools for motivating students

\section{B. Teaching Philosophy Statement}

The teaching philosophy statement is a statement of your personal ideology about what engineering should be and what is should aim to achieve. It is personal but needs to take into account the mission and goals of the institution and must be regularly reviewed and updated. The statement should contain your goals of engineering education at the level you are teaching, the needs of the students, your role of a teacher, how instruction should be organized and delivered, your definition of student success, your proposal to achieve the goals set for yourself and how you propose to continue working on your professional development. [2]

We have proposed the faculty the below framework that would help them draft their teaching philosophy statement. The faculty were asked to divide their statement into 4 sections.

1) View of leaning: How do you conceptualize learning? What do we mean by learning and how does it occur? How do you facilitate this process in the classroom? How have your experiences influenced your view of learning?

2) View of Teaching: What is teaching? What is the professor's role in the classroom? How does teaching 
facilitate the learning process? How do you challenge students intellectually while supporting those with different learning styles and abilities? How have your experiences influences your view of teaching?

3) Goals for Students: What do you expect your students to learn? What goals do you set for your classes and why? How do you work to help your students achieve your goals? What do you value in terms of student learning (e.g., writing, problem solving, critical thinking, and content knowledge)?

4) Implementation of Philosophy: How do the ideas you've discussed thus far influence what you do in your classroom? How do you operationalize and implement your philosophy of teaching? Reflect on your course materials, assignments, projects, and teaching style.

\section{Course Description Document}

Course description document is a short, informational statement about the approach and content of a course. Anyone browsing the course description document should be able to determine very quickly what the course is about.

The course description document is divided into 8 sections.

1) Basic Details: This section contains the title of the course, name of the instructor, number of class hours per week and the room number of the classroom if necessary.

2) Course Overview: This section contains a brief overview of the course along with the test portion for the assignments and mid examinations.

3) Course Objectives: This section contains a list of objectives that the students will be able to achieve at the end of the course.

4) Course Outcomes: This section contains a list of outcomes that the students are expected to achieve at the end of the course.

5) Detailed Schedule: This section contains a detailed list of name of the topic being taught and its associated topic outcome.

6) List of textbooks and references: This section contains list of text books and other references which can be referred during the course.

7) Activities conducted in the class: This section contains list all activities that the faculty will be conducting during the class.

8) Grading Criteria: This section contains the grading criteria and pattern for the evaluation of the course.

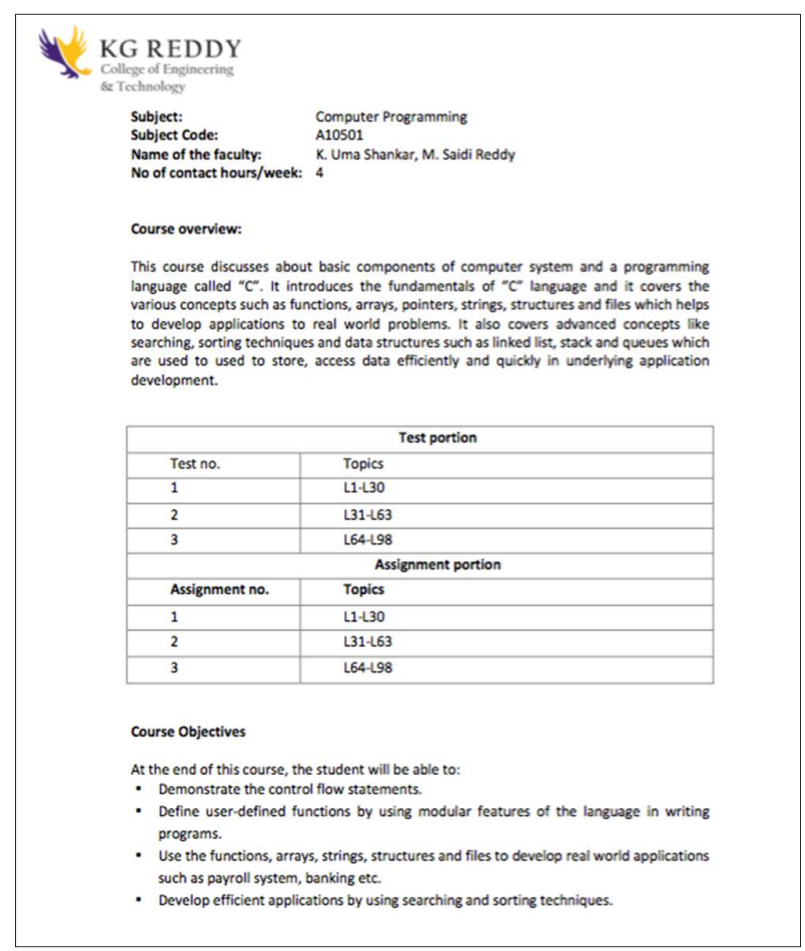

Fig. 1First 3 sections of course description document

Fig. 2Section 4,5 of course description document

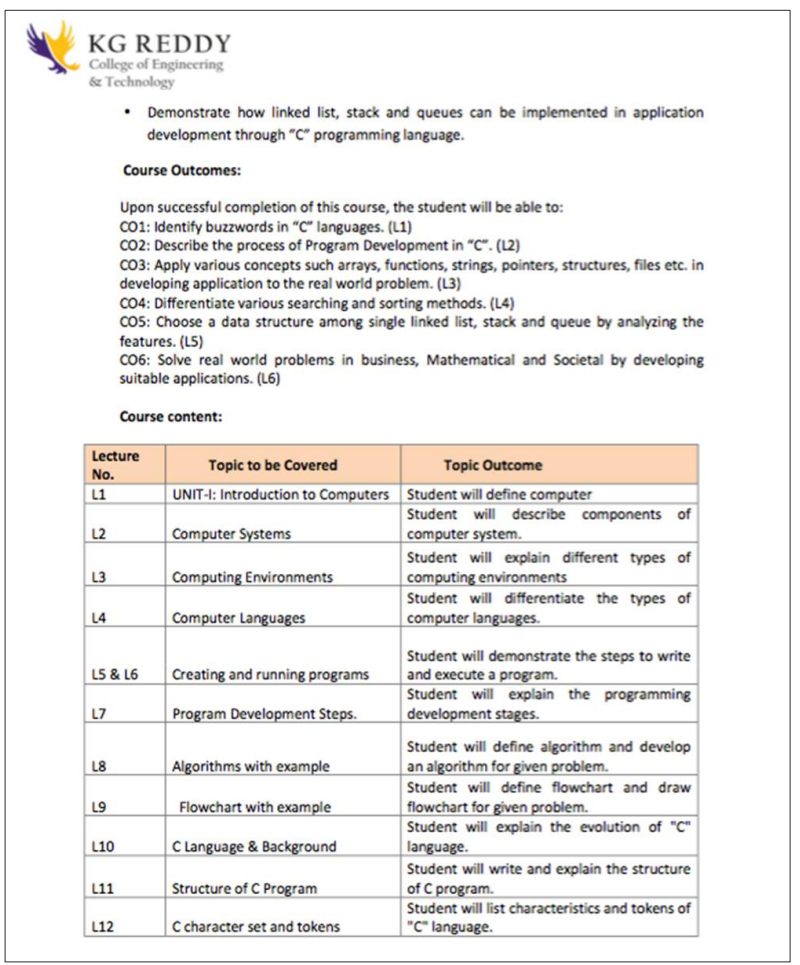




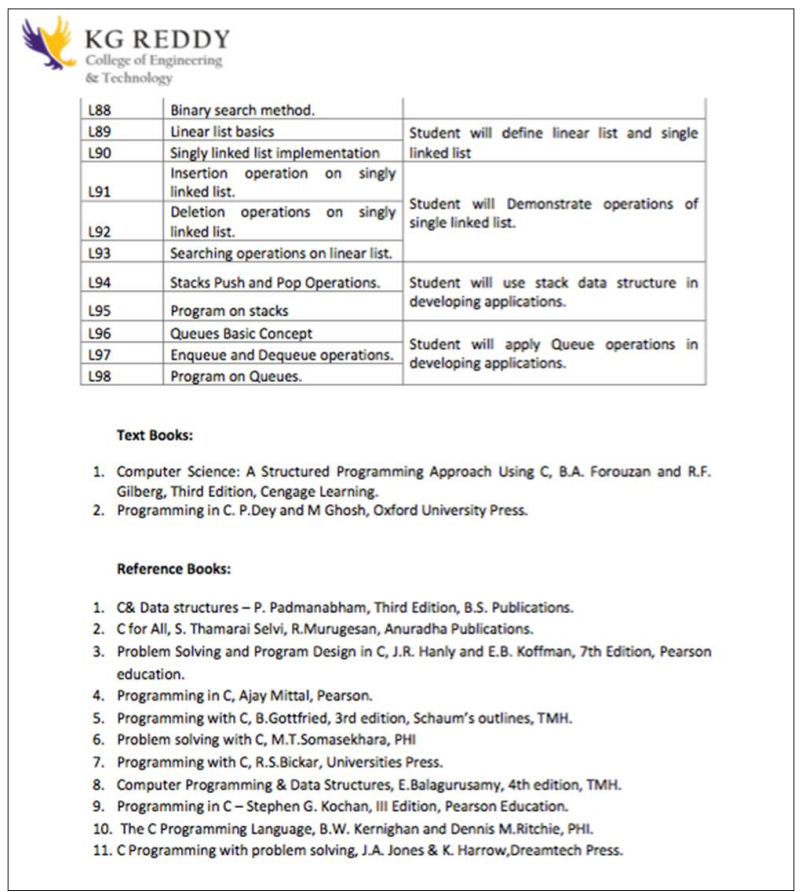

Fig. 3Section 6 of course description document

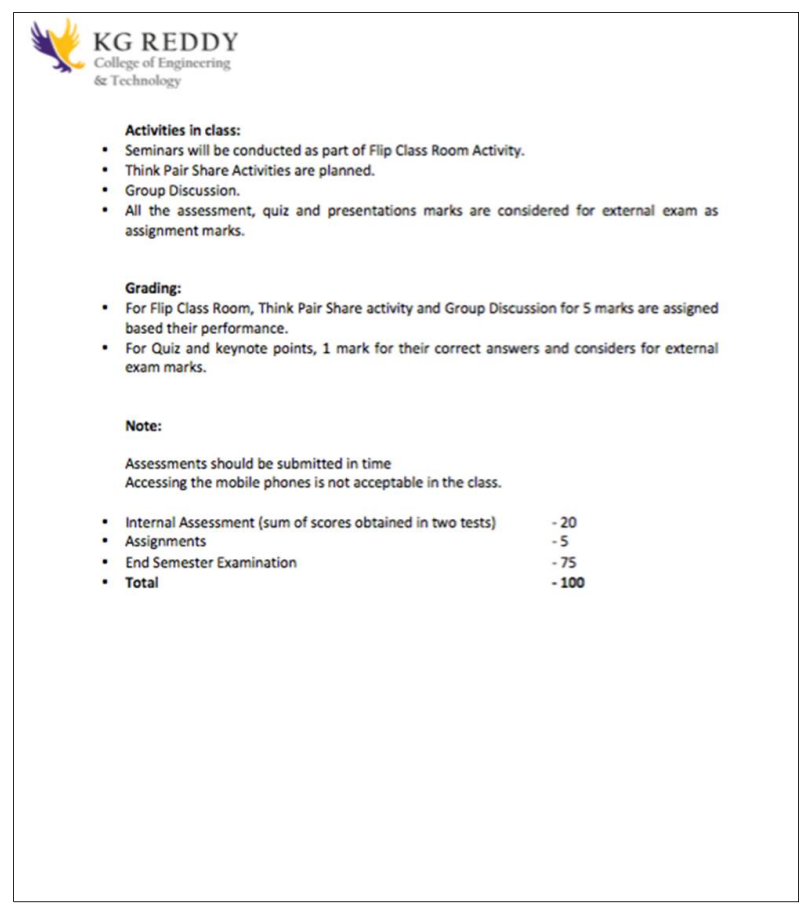

Fig. 4Section 7, 8 of course description document

\section{Lecture Delivery}

Few of the personality traits of the millennial learners to be taken into consideration are their short attention span and their affinity to enjoy social interaction. Research suggests thatthe concentration level of a student keeps dropping as shown in the below figure.

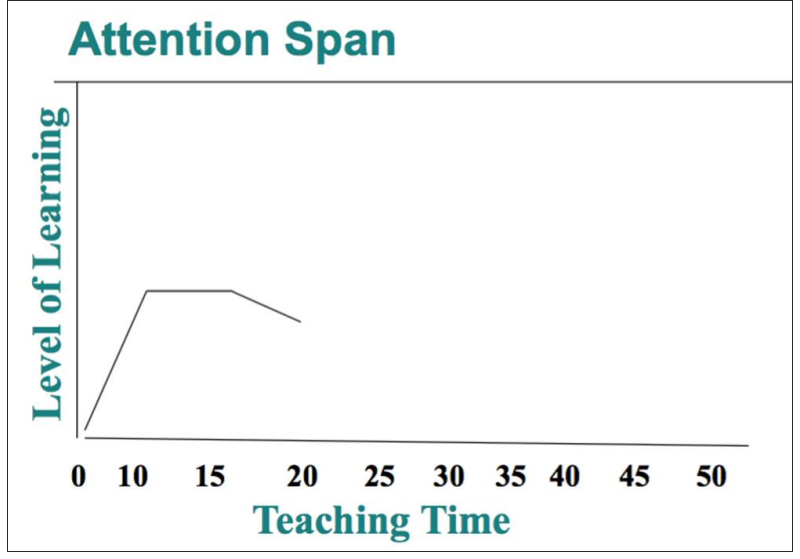

Fig. 5Attention span of a student inside the classroom [3]

This issue needs to be addressed immediately to ensure effective learning during the class. It has been suggested that by indulging students small active learning activities in the class improves their attention span and which ensures better learning as shown the below figure.

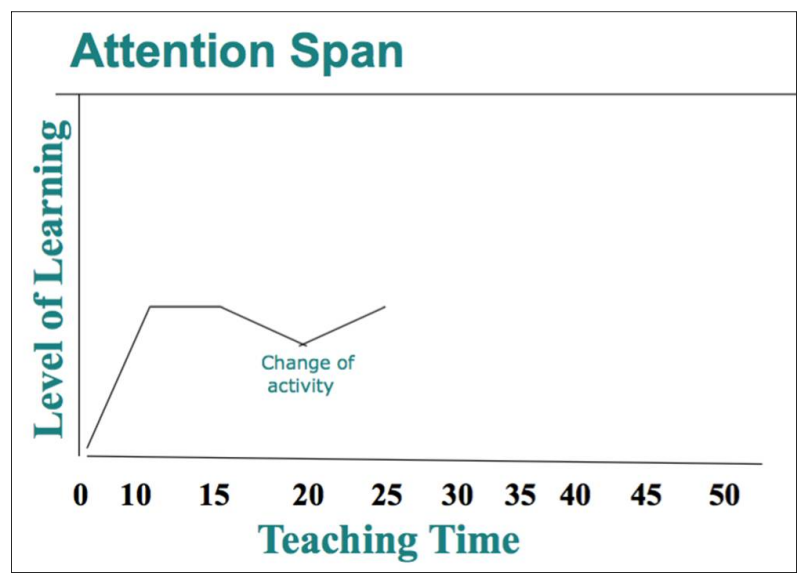

Fig. 6 Attention span of a student after activity[3]

Various activities such as think pair share, TAPPS, group activities, online quizzes etc. can be conducted in the class. [4]

Taking all the above into consideration, all the faculty were suggested to follow the below was lecture structure.

50 minute lecture to be divided into 5 segments

- Day's objective/s

- Segment 1 of the day's topic

- $\quad$ Short assessment/ activity

- $\quad$ Segment 2 of the day's topic

- $\quad$ Summing up-key take away.

The faculty development workshop was ended with a Q\&A session during which faculty clarified all the necessary doubts with us. 


\section{Follow up and feedback session}

During the next 2 weeks, the members of CEED had scheduled two individual meeting with each of the faculty in the college to help them through the transformation. During the first meeting, feedback and suggestions were provided to help faculty complete the course description document. The hard copy of course description documents were provided to the students before the start of the semester.

During the $2^{\text {nd }}$ feedback meeting with each faculty, the faculty were expected to share any challenges that they have been facing during the new lecture delivery structure. The concerns faced by few faculties were addressed and necessary suggestions were provided to overcome them. This process ensured a smooth transition of the new teaching methods during the semester.

\section{Results and Conclusion}

After both the feedback sessions with the entire faculty individually, the students were asked to fill a feedback form for the entire faculty teaching them. The analysis showed that most of the faculty startedfollowingthe new proposed delivery structure in their classroom. Analysis also showed that a great improvement in the level of student engagement and quality of learning during the class. The new methods also increased the average attendance percentage of the students for the semester. Following are analysis taken from student online feedback.

How much percentage of faculty started teaching the class with an ice-breaker?

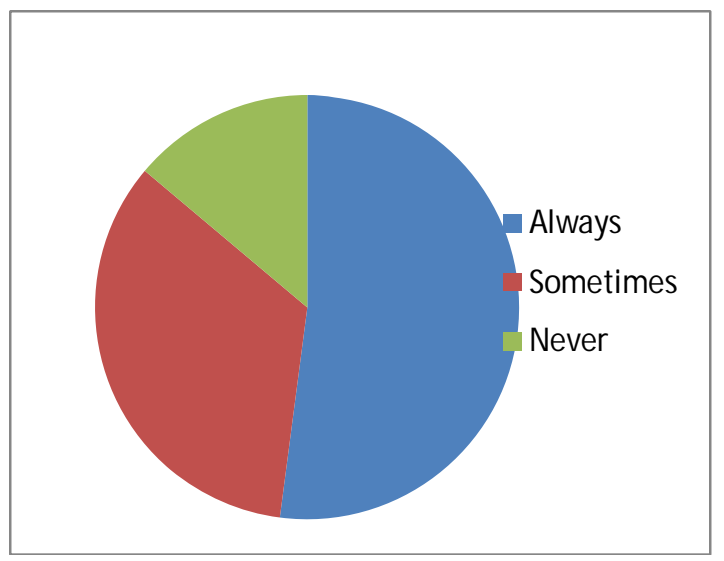

How much percentage of faculty started teaching the class with the lecture objectives?

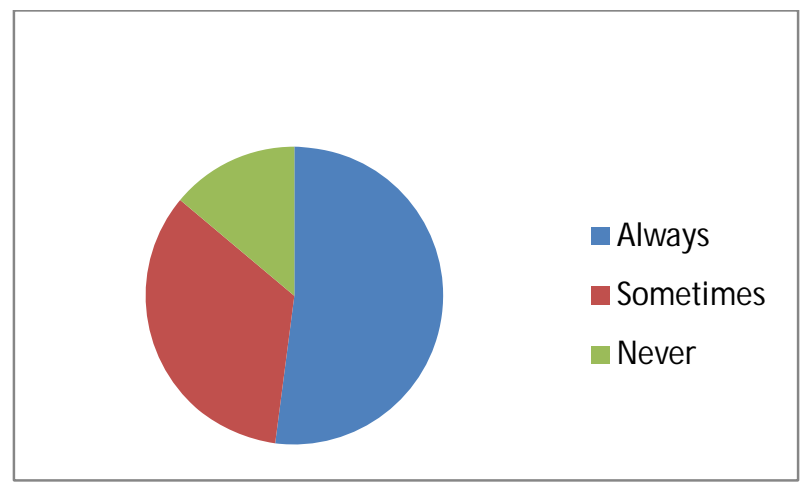

How much percentage of faculty practiced active learning methods in the class?

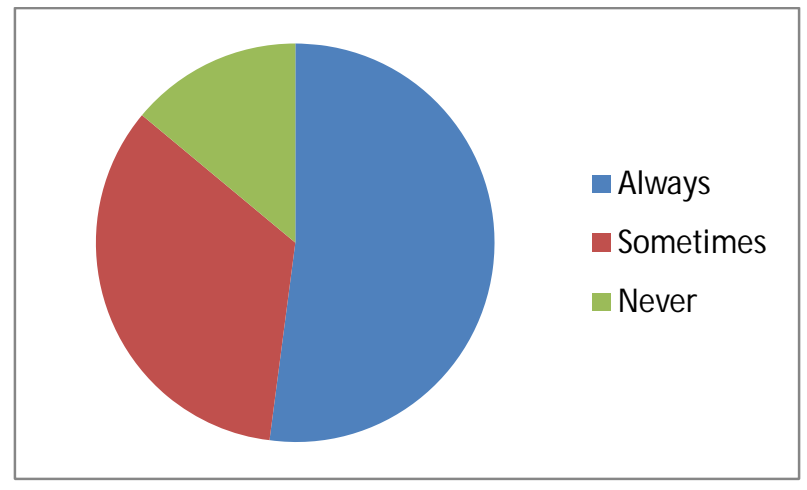

How much percentage of faculty ended the class summarizing the class's objectives?

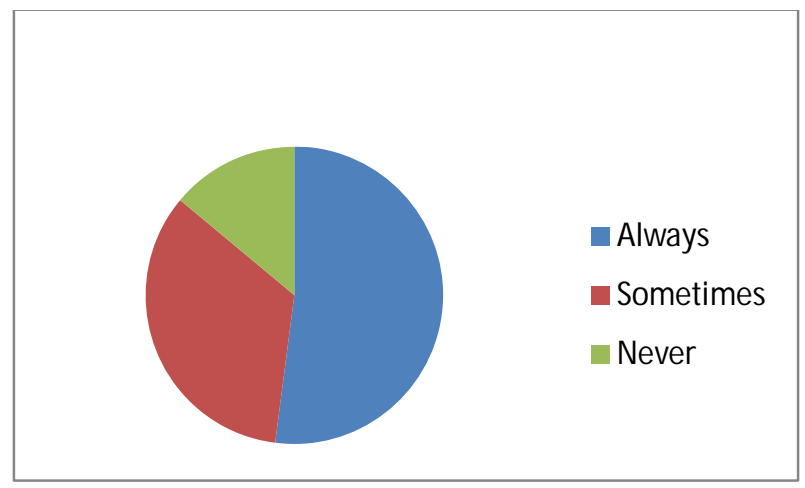

How well did the activities performing in the class help students to learn the subject better?(1-5 scale, Excellent-5 to Nouse-1) 


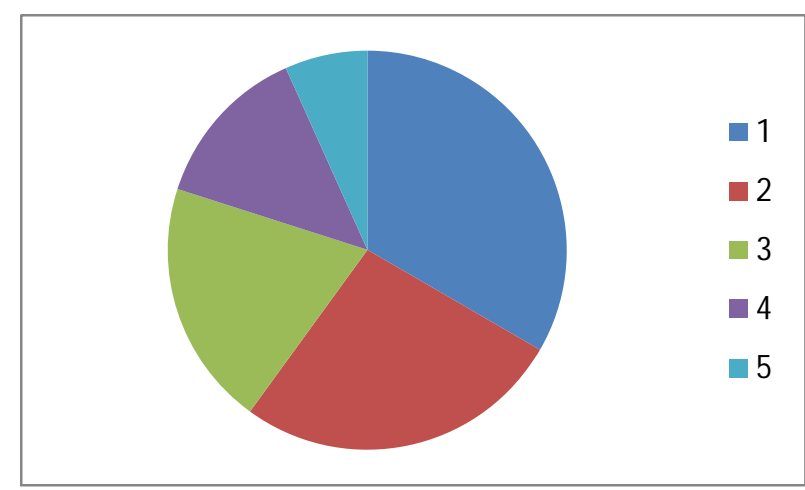

Did the activities being performed in the class making students more interested during the lecture ?(1-5 scale, Excellent-5 to Nouse-1)

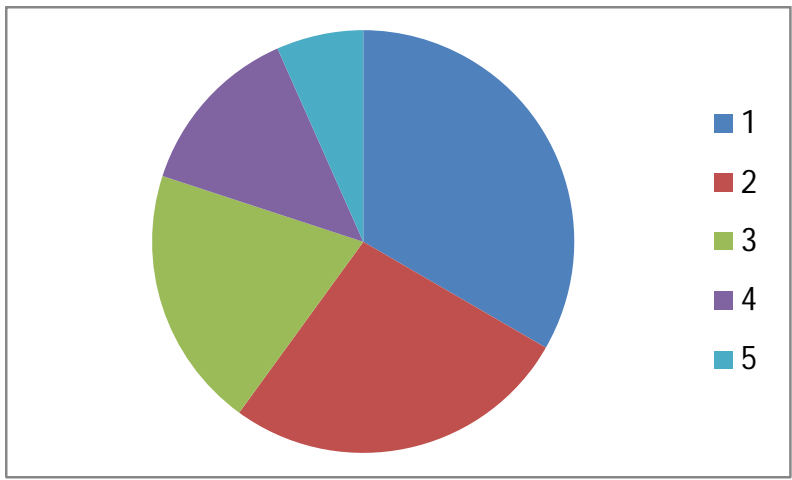

\section{Future Scope of work}

We have contacted two doctoral students in the department of engineering education at Purdue University who agreed to help us as advisors. They will be working with us on designing a more detailed evaluation system to understand the impact of the active learning methods on students learning.

Two members of the CEED team will also be experimenting a blended course structure in the upcoming semester and evaluate its results. Upon receiving positive results, we plan to introduce it entirely into the curriculum from the next academic year.

\section{Acknowledgement}

Firstly we would like to the chairman and director of $\mathrm{KG}$ Reddy College of Engineering and Technology,Ln. K. Krishna Reddy, and Dr. M.Madhusudanan Nair respectively for their constant support for this initiative. We would also like to thank IUCEE for providing us the platform to learn various teaching learning practices in the field of EE.

\section{References}

C. Meyer and T.B. Jones, Promoting active learning: Strategies for the college classroom, San Francisco, JosseyBass, 1993.
R.M. Felder \& R. Brent. (2003). "Learning by Doing." Chem. Engr. Education, 37(4), 282-283. <www.ncsu.edu/felder- public/Columns/Active.pdf>. The philosophy and strategies of active learning.

R.M. Felder. (1994). “Any Questions?” Chem.Engr. Education, 28(3), 174-175. <www.ncsu.edu/ felderpublic/Columns/Questions.pdf $>$. Illustrative questions for engineering and science courses that can serve as the basis of active learning exercises

R.M. Felder \& R. Brent. (1999). “FAQs-2.”Chem. Engr. Education, 33(4), 276-277. <www.ncsu.edu/ felderpublic/Columns/FAQs-2.html>. Responses to the questions "Can I use active learning exercises in my classes and still cover the syllabus?" and "Do active learning methods work in large classes?"

M.J. Prince. (2004). "Does Active Learning Work? A Review of the Research." J. Engr. Education,93(3), 223231. <www.ncsu.edu/felder-public/Papers/Prince_AL.pdf>. A summary of research evidence for the effectiveness of active learning. 